\title{
Research on Design and Magnet Assembly Process of Multivariate and Multi-Roll Permanent Magnetic Separator
}

\author{
Hongguang $\mathrm{Jiao}^{\mathrm{a}}$, Changliang Shi ${ }^{\mathrm{b}}$, Ruixia $\operatorname{Tian}^{\mathrm{c}}$ \\ School of Material Science and Engineering, Henan Polytechnic \\ University, 454003, Jiaozuo, China \\ ajhghpu@126.com, bscl303@126.com, 'tian55rx@163.com
}

\section{Keywords: Magnetic Separator; Permanent Magnet; Magnetic System Design}

\begin{abstract}
Magnetic separation is broadly applied to the recycling processing of industrial solid waste, conventional permanent magnetic roll can't separate various magnetic materials from waste residue at the same time. Through theoretical analysis and numerical simulation, this paper matched fan-shaped magnetic steel as disc and developed "Interval alternative process of false magnet", this solved the problem of the magnet assembly. On this basis, a multi-roll permanent magnetic separator was manufactured, by connecting multiple magnetic in series. This equipment can not only get different magnetic products, but also can complete roughing and cleaning assignments, and eased gradation requirements of repairing material significantly. An experiment of choose iron from zinc volatilization kiln furnace slag for a zinc smelter, iron recovery and grade is $76.33 \%$ and $62.31 \%$, respectively. This separation roller can also be used in ore, nonmetalliferous ore sorting and powder materials purification, etc.
\end{abstract}

\section{Introduction}

In recent years, the accumulation of industrial waste, pollution and resource waste problem becomes more and more obvious, permanent magnetic rollers widely applied in the process of its resources. But conventional magnetic separator generally applies only coarse materials scavenging, cannot separate various magnetic materials simultaneously, and due to defects of magnetic design and mechanical structure, sorting accuracy is difficult to meets the requirements [1-2].According to complicated composition and gradation wider characteristics of industrial wastes, the author developed a multi-roll permanent magnetic separator, which realized comprehensive recycling of valuable components in the industrial waste by connecting several different separation condition magnetic rollers in series.

\section{Design of Magnetic System}

Design Methodology of Magnetic System. Magnetic roller appeared in 1981, whose mechanical structure and magnetic system design are improving continuously, etc. The most common permanent magnetic systems are as follow: Interlaced superposition [2], repel extruding [3] and goods font [4], ect (Table 1).

High-Force permanent magnetic roller and rare earth permanent magnetic roller have a high magnetic intensity. Multipolar magnetic permanent magnetic roller is goods font, N-S staggered, magnetic field intensity only have $0.38 \mathrm{~T}$, big magnetic process, and it's able to achieve a multi-level separation for a single mineral. So when design the magnetic, it is important to consider various sorting factors, weigh on two contradictory indexs of magnetic field intensity and magnetic depth, get reasonable decorated magnetic roller to improve separating efficiency.

Magnetic material will tumble in the process of magnetic with flip magnetic, this helps to disperse magnetic group, and solve problem of inclusion. In the sorting out separation, magnetic 
particles overcome the other mechanical force, break away from the material layer of crude ore, become concentrate under the leading role of magnetic force, corresponding concentrate grade is high $[5,6]$. We need to carry on the multiple selections to improve the product quality constantly, therefore the modularized design shall be taken into consideration, through the combination and superposition of modules to realize effective sorting.

Table 1 Technical indexes of permanent magnetic separation roller

\begin{tabular}{|c|c|c|c|c|}
\hline name & $\begin{array}{l}\text { design characteristics } \\
\text { of magnetic }\end{array}$ & $\begin{array}{l}\text { magnetic field } \\
\text { intensity and process } \\
\text { of roller surface }\end{array}$ & $\begin{array}{l}\text { structure form of } \\
\text { magnetic roller }\end{array}$ & sorting effect \\
\hline $\begin{array}{c}\text { high-Force } \\
\text { permanent } \\
\text { magnetic roller }\end{array}$ & $\begin{array}{l}\text { Re magnetic ring } \\
\text { piece and stalloy } \\
\text { staggered form } \\
\text {, uneven distribution } \\
\text { magnetic }\end{array}$ & $1.3 \mathrm{~T}, 50 \mathrm{~mm}$ & $\begin{array}{l}\text { single magnetic } \\
\text { roller, single field }\end{array}$ & $\begin{array}{l}\text { confined to a single } \\
\text { weak magnetic and } \\
\text { coarse minerals, low } \\
\text { separating grade }\end{array}$ \\
\hline $\begin{array}{c}\text { rare earth } \\
\text { permanent } \\
\text { magnetic roller }\end{array}$ & $\begin{array}{l}\text { two same polarity } \\
\text { magnets relative } \\
\text { extrusion together, } \\
\text { the middle is soft iron } \\
\text { as boots }\end{array}$ & $2 \mathrm{~T}, 30 \mathrm{~mm}$ & $\begin{array}{l}\text { multi-layer } \\
\text { magnetic roller, } \\
\text { single field }\end{array}$ & $\begin{array}{l}\text { confined to a single } \\
\text { weak magnetic and } \\
\text { fine minerals, low } \\
\text { recovery }\end{array}$ \\
\hline $\begin{array}{c}\text { multipolar } \\
\text { magnetic } \\
\text { permanent } \\
\text { magnetic roller }\end{array}$ & $\begin{array}{l}\mathrm{NdFeB} \text { permanent } \\
\text { magnetic N-S } \\
\text { staggered in } \\
\text { horizontal, formed } \\
\text { multilayer poles }\end{array}$ & $0.38 \mathrm{~T}, 80 \mathrm{~mm}$ & $\begin{array}{l}\text { multi-layer } \\
\text { magnetic roller, } \\
\text { single field }\end{array}$ & $\begin{array}{l}\text { confined to a single } \\
\text { strong magnetic } \\
\text { minerals, obvious } \\
\text { separation effect }\end{array}$ \\
\hline
\end{tabular}

Magnetic System Matched with Fan Magnets. Multi-roll permanent magnetic separator arranged a number of magnetic roller with same structure in series, the magnetic system of a magnetic roll constituted by many fan magnets with same specification and radial magnetization. According to the principle of magnetic technology, magnets arranged along a circle to different pole, through the annular splicing to increase magnetic process. So that to construct magnetic system of the magnetic roller.

Constructed finite element model of 1/4 fan-shaped magnetic by Ansys and applied load to the radius in extrusion, distribution characteristics of magnetic induction (B) (figure 1), it is observed that magnetic induction is high along the radius, and the magnetic flux leakage is less which illustrate that magnetic field strength is higher than single block ring magnets itself, verify the correctness of design stitching magnetic department.

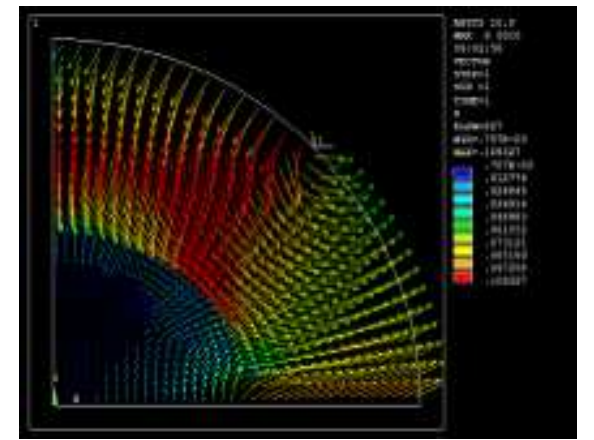

Fig.1 Distribution of magnetic induction
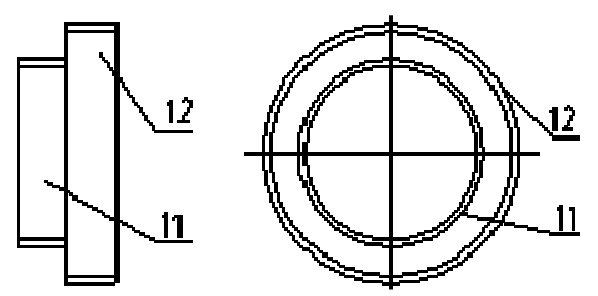

Fig.2 Main-view and side-view of the Nylon limited sleeve (11 sleeve section, 12 outside retaining ring )

Permanent Magnet Assembly. Permanent magnet assembly is the difficulty point of permanent magnetic separator, for avoiding damaging magnetic poles because of extrusion, we designed "Interval alternative process of false magnets(non-magnetic stainless steel replacement with the 
same specification of permanent magnet )" to realize the permanent magnet assembly. Fixture is mainly several nylon sleeves: A thread of nylon positioning sleeve, one block of a set of nylon limit sleeve (figure 2). A non-magnetizer protective tube and a non-magnetizer stainless steel pressure tube which circle around the multiple threads (figure 3 ).

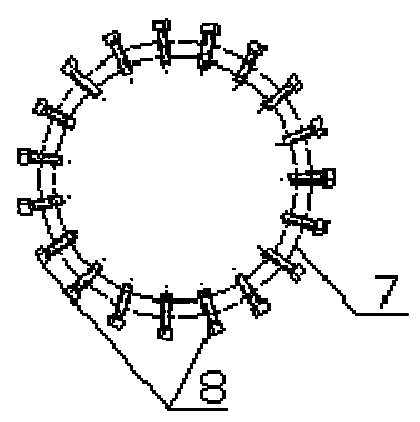

Fig.3 Structure of circular stainless steel pressured tube

(7 non-magnetizer stainless steel pressure tube, 8 puller bolt)

General assembly process of magnetic roller can see fig.4: First fixed the position of nylon positioning sleeve, inner shaft and non-magnetizer stainless steel barrel. Then take annular end faces as a benchmark the inside with nylon positioning sleeve, turn multiple fake magnets (non-magnetic stainless steel replacement) into the circle gap between inner shaft and magnets protect barrel. At this moment, magnetic protect tube and non-magnetizer stainless steel pressure tube moving toward the false magnets along the axial, pressure compaction false magnets through tight puller bolt. Then use fan permanent magnet to replace the same size false magnets at intervals, so a group of ring permanent magnets was assembling. When start the second group of assembly, first use tape to fixed false magnets, stopped stainless steel tube and magnetic protect tube at the position of half of the axial length position of false magnet, then removed tape. Finally, use nylon tubes to extrude the permanent magnet ring, to eliminate the axial clearance. Glued at the same time, after the glue solidified to make a complete transmission roller. Finished the magnetic assembly.

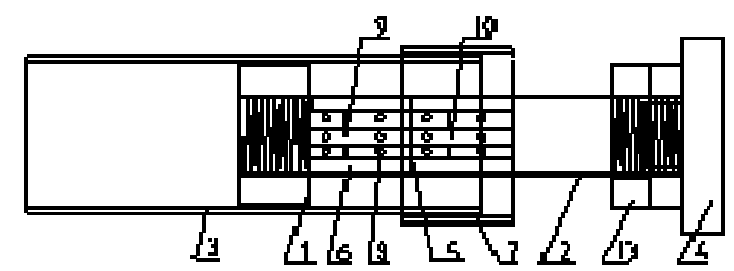

Fig.4 Diagrammatic illustration of second circular stainless pressured tube assembly 1 , nylon positioning tube; 2 , inner shaft; 3 , non-magnetic magnetic protect tube; 4 ,nylon limited sleeve; 5 , false magnets; 6 , fan permanent magnets; 7 , non-magnetic stainless pressured tube; 8 , puller bolt; 9 , the first group of annular extrusion magnets; 10 , the second group of annular extrusion magnets; 13 , nylon tube.

\section{Structure Characteristics of Multivariate and Multi-roll Permanent Magnetic Separator and Separation Experiments}

Structure of Equipment. Connect multiple magnetic rollers in series can build multivariate and multi-roll permanent magnetic separator. The machine includes: frame, multilayer horizontal belt, feed hopper set in the upper belt, bagging hopper installed below a conveyor belt. Conveyor belt using bottom-up step-wise dislocation arrangement and the transmission device drivers, the drive roller (active roller) is magnetic roller structure in each layer (figure 5). 

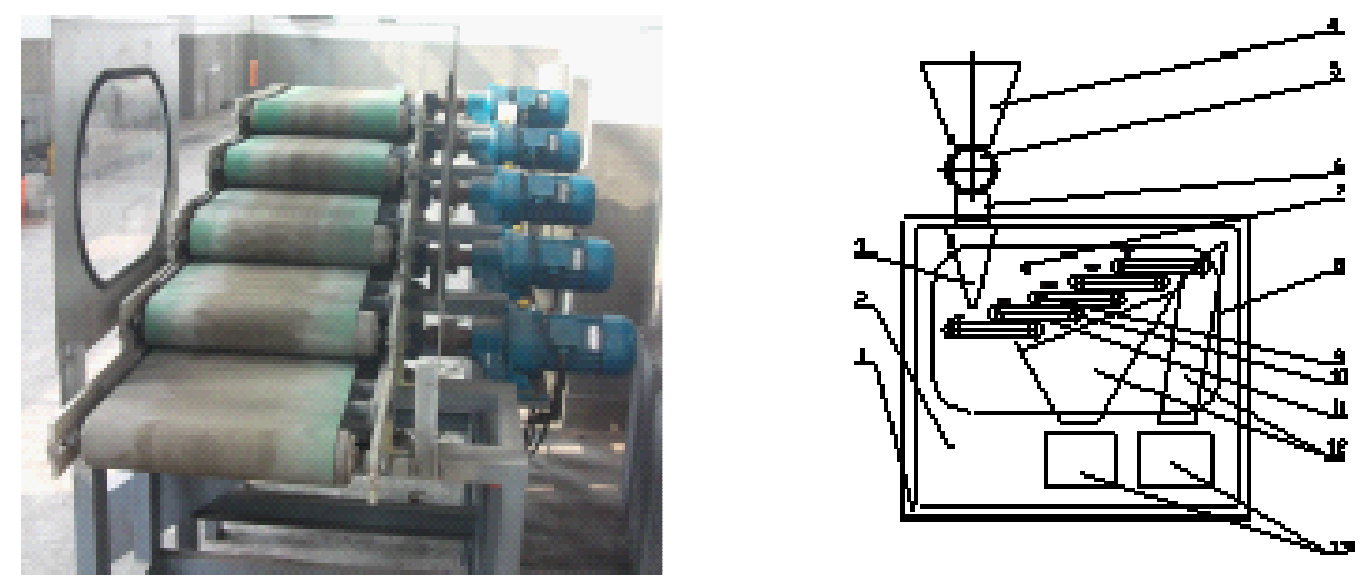

Fig.5 Whole structure of the new roll magnetic separator

1, frame; 2,sealed cover; 3,funnel I with undertake materials; 4,feed hopper; 5 ,quantitative feeder; 6,material sealed cover; 7,tighten screws; 8,transparent maintenance window; 9,drive roller(active roller); 10, drive roll; 11,conveyor belt; 12,bagging hopper; 13,drawer silo.

Toward the layout magnetic roller, the two layers of roller staggered a certain distance, just meet every level of magnetic roller permanent magnet field not interfere with each other in sorting space. For transmission mode, permanent roller and driving spindle connected with cooperation, that is permanent magnet rotated together with outer roller in the transmission of spindle drive down, come about alternating direction magnetic, made non-magnetic materials removed effectively, and promoted the grade of separating materials.

Structural Features. Each level of magnetic roller is equipped with single frequency to control and realize material satisfactions gradually; Therefore, we can adjust the speed of belt, thickness of the conveyor belt, magnetic roller materials, and magnetic roller layout, to meet different sorting requirements. In the selection of magnetic roller materials, each level of roller can adopt different magnetic material, field intensity changes from weak to strong while from a bottom-up direction, making this permanent magnetic separation machine have the effect of weak magnetic separation, middle magnetic and the strong magnetic separation, realizing separation of different magnetic components at the same time. If each class magnetic material is same, we can adjust thickness and speed of belt convey. In the cases of same magnetic material and thickness of the conveyor roller : Control magnetic roller speed increases from up to down, in the background of the same field, both can satisfy the useless mineral cast and enhance valuable mineral enrichment, finally, improve the magnetic concentrate grade.

Separation Experiments. The choosing zinc volatilization kiln furnace slag for a zinc smelter as sorting object, zinc slag grinding into: $0-0.45 \mathrm{~mm}, 0.45-0.75 \mathrm{~mm}, 0.75-1 \mathrm{~mm}$, conduct three selection respectively and separation experiments of iron contained, experimental results see table 2 .

Table 2 Test data of zinc kiln slag for Fe magnetic separation

\begin{tabular}{cccccc}
\hline $\begin{array}{c}\text { sorting } \\
\text { number }\end{array}$ & $\begin{array}{c}\text { partical size } \\
(\mathrm{mm})\end{array}$ & $\begin{array}{c}\text { gross } \\
(\mathrm{g})\end{array}$ & $\begin{array}{c}\text { concentrate } \\
(\mathrm{g})\end{array}$ & $\begin{array}{c}\text { yield } \\
(\%)\end{array}$ & $\begin{array}{c}\text { grade of } \\
\text { Fe}(\%)\end{array}$ \\
\hline 1 & $0-0.45$ & 10.0079 & 6.2557 & 62.51 & 49.54 \\
2 & $0-0.45$ & 6.2557 & 4.6840 & 74.88 & 59.92 \\
3 & $0-0.45$ & 4.68408 & 3.6477 & 77.88 & 61.72 \\
1 & $0.45-0.75$ & 10.0024 & 6.1017 & 61.00 & 48.00 \\
2 & $0.45-0.75$ & 6.1017 & 4.6171 & 75.67 & 54.37 \\
3 & $0.45-0.75$ & 4.6171 & 4.1451 & 89.78 & 63.70 \\
1 & $0.75-1$ & 10.0017 & 5.6888 & 56.88 & 50.69 \\
2 & $0.75-1$ & 5.6888 & 4.3212 & 75.96 & 55.56 \\
3 & $0.75-1$ & 4.32124 & 3.9882 & 92.29 & 62.31 \\
\hline
\end{tabular}


From table 2 we can draw: Iron in Zinc slag furnace after much section, yield and recovery were improved obviously. And the separating effect more obvious with the increasing of particle size, because of magnetic susceptibility and particle size of furnace slag into a direct relationship. Iron recovery and grade is $76.33 \%, 62.31 \%$ when particle size fraction is $0.75-1 \mathrm{~mm}$, respectively.

\section{Conclusions}

This paper matched fan-shaped magnetic steel with same specification and radial magnetization as disc which arranged along a circle, multiple disk extrusion can constitute the separation of magnetic separation roller. The developmental "Interval alternative process of false magnets", which solved the problem of the magnet assembly, thus it provide basic design modules for the new permanent magnetic separator. We arranged a number of magnetic rollers with same structure in series to form multivariate and multi-roll permanent magnetic separator, which can realize various magnetic separation condition in the single separate, it not only realized comprehensive recycling of valuable components in the industrial waste, but also be used in ore, nonmetalliferous ore sorting and powder materials purification in building materials, ceramic, abrasive, etc.

\section{Acknowledgement}

The authors acknowledge the financial support from Henan Innovation Project for University Prominent Research Talents (2009HATIT020), Henan key science and technology research projects (117309), and Open Fund Project of Key Laboratory of Coal Processing and Efficient Utilization, Ministry of Education (CPEUKF08-03).

\section{References}

[1] B·R·AErWei Watson, D·Henderson: Metallic Ore Dressing Abroad, Vol.3(2001), p.15

[2] Shuhui Wang, B·R·AErWei Watson: Metallic Ore Dressing Abroad, Vol.10, ( 1996), p.27-31. (In Chinese)

[3] Dingwu Feng: Metal Mine, Vol. 254(1997), p.34(In Chinese)

[4] Zhongyuan Sun: Non-ferrous Mining and Metallurgy, Vol. 22(2006), p.130(In Chinese)

[5] M. Ziemski, P.N Holtham: Minerals Engineering, Vol. 18(2005), p.1405

[6] ARVIDSON, Bo, R, WO Patent 2006/072661 A1. (2006)

[7] Ruimin Zhao, Enhai Dong: Non-metallic mines, Vol. 32(2009), p.64 (In Chinese)

[8] S.Nedelcu, J.H.P. Watson: Minerals Engineering, Vol. 15(2002),p.355 